\title{
ALBERTO GONZÁLEZ POZO
}

\section{Arquitectura y urbanismo en Iberoamérica}

universo por explorar

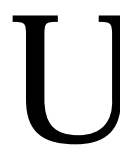

NA DE LAS RESTRICCIONES QUE ME IMPONGo al escribir este ensayo sobre arquitectura latinoamericana es que excluyo a M éxico como tema central de reflexión. Parece un contrasentido dejar fuera a nuestro país cuando se trata de ver el panorama de la arquitectura y el urbanismo iberoamericanos en su conjunto. En este caso, se trata de un recurso que me obliga a salirme de un ámbito de experiencias personales y fuentes bibliohemerográficas accesibles en el que me siento relativamente seguro, para adentrarme en un territorio mucho menos conocido o francamente ignoto. Pero excluir a M éxico y sus edificaciones como tema central de este texto no implica olvidarme de mi realidad. Al contrario: las analogías y diferencias entre nuestra cultura arquitectónica y la de otros pueblos hermanos de América son interesantísimas y las mencionaré a medida que vayan apareciendo.

\section{Las diversas preexistencias indígenas}

Sudamérica precolombina muestra gran variedad regional en sus asentamientos y sus arquitecturas. M ientras en la extensa cuenca amazónica al noreste florecieron aldeas agrícolas de subsistencia y en las regiones pampeanas del sureste predominaron grupos nómadas, toda la cordillera de los Andes, sus valles altos y su litoral Pacífico fueron escenarios de civilizaciones agrícolas que siguen etapas parecidas a las de M esoamérica. La arqueología sudameri- 
DOI: http://dx.doi.org/10.22201/iie.18703062e.2004.85.2412

88

ALBERTO GONZÁLEZ POZO

cana todavía está construyendo modelos y cronologías que expliquen mejor lo ocurrido. ${ }^{.}$Si esto es difícil de entender ahora, lo era mucho más hace cuatro décadas, cuando Jorge $\mathrm{E}$. $\mathrm{H}$ ardoy logró reunir en una sola obra un panorama del urbanismo precolombino en todo el Continente Americano, ya que por aquel entonces incluso los modelos explicativos sobre M esoamérica estaban revisándose. ${ }^{2}$

\section{Las etapas formativas}

En Sudamérica hay un largo proceso entre to ooo y 2000 años antes de nuestra era, cuando aparecen los primeros ocupantes de la costa y del altiplano, y se transita gradualmente de culturas nómadas a otras sedentarias en las que se inicia la domesticación de especies vegetales comestibles y de animales domésticos (Ilamas, vicuñas, alpacas, perros y patos), así como la construcción de aldeas, como actividades predominantes. Luego ocurre un periodo de transición, todavía precerámico, entre 2000 y I400 a.C., en que aparecen los primeros asentamientos compactos con núcleos ceremoniales tanto en la Costa del Pacífico (en Caballo M uerto, Aspero, El Paraíso y Paracas) como en los valles al tos de la cordillera de los Andes (en Kotosh y H uaricoto).

Algunos de estos sitios evolucionaron en la siguiente etapa entre I40o y soo a.C., Ilamada H orizonte Temprano, correspondiente a la formación de las culturas-madre de Sudamérica. Es cuando surgen montículos piramidales que adoptan disposiciones en forma de $U$. Algunos muestran decoración arquitectónica antropomorfa como la huaca (pirámide) de los Reyes en CabaIlo M uerto, o símbolos cósmicos como en Kotosh. Este florecimiento culmina en Chavín de $\mathrm{H}$ uantar, importante sitio arqueológico que floreció entre 800 y 200 a.C. y en cuyo centro ceremonial ya están presentes rasgos que aparecerán repetidamente en etapas posteriores: pirámides escalonadas, patios hundidos y cabezas-clavas de piedra labrada. ${ }^{3}$ Ya en esta época aparece la

I. La variedad y nomenclatura de cronologías sobre la arqueología sudamericana es muy grande. Casi cada uno de los autores que se ocupan del urbanismo y la arquitectura precolombinas citados en este artículo propone una cronología distinta. N osotros hemos optado por la que proponen Michael Coe, Dean Snow y Elizabeth Benson en Atlas of Ancient America, N ueva York-O xford, Facts O n File, 1986, según la cual se alternan periodos con horizontes.

2. Jorge E. H ardoy, Ciudades precolombinas, Buenos Aires, Infinito, I964.

3. Federico Kauffman D oig, M anual de arqueología peruana, Lima, PEISA, 1973, pp. 94-95. 
I. Fortaleza de Sacsahuamán a base de megalitos, Cuzco, Perú, siglo xv. Foto: Alberto González Pozo.

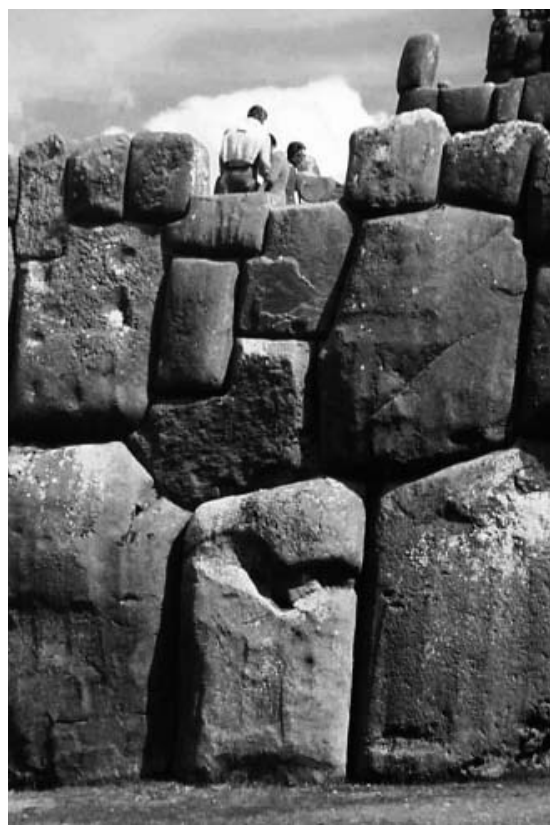

metalurgia indígena sudamericana, con ejemplos desde el sur de Colombia hasta el norte de Argentina. C on C havín ocurre lo mismo que con La Venta en M esoamérica: durante mucho tiempo se consideró origen de la arquitectura olmeca cuando en realidad representa una de las últimas etapas de esa cultura primigenia.

En algunos sitios como los valles costeros de los ríos N epeña y C asma, cercanos a Chavín y bajo su influencia, se desarrollan otros rasgos que guardan un impresionante paral elismo con el preclásico y clásico mesoamericano, particularmente la zona maya: las plataformas escalonadas, algunas con frisos o mascarones monumentales y otras con nichos, como en el Tajín. Es el caso de M oxeque, donde, por cierto, la plataforma piramidal está rematada por templos dobles, como los que levantaron los mexicas en M esoamérica muchos siglos después. ${ }^{4}$ O tra cultura regional de esta etapa formativa es la de gunos monumentos mesoamericanos muy tempranos con 'mascarones' adosados a sus paredes." 
Garagay, dentro de la zona metropolitana de Lima, cuyos vestigios muestran frisos y mascarones policromados de gran calidad. 5

Por la misma época florece en la península de Paracas otra cultura, conocida con ese mismo nombre, que impulsa el género de necrópolis, con pozos excavados en forma de botella para los enterramientos. Al parecer, en ella se inician las "marcas" o gigantescos dibujos sobre la tierra formando líneas 0 símbolos, como árboles-candelabro. ${ }^{6}$ Este rasgo de arquitectura de paisaje a gran escala prepara manifestaciones en la cultura nazca que floreció después.

\section{Las etapas intermedias}

Al finalizar el H orizonte Temprano, alrededor de 400 a.C., Chavín y Paracas pierden importancia y se inicia un nuevo lapso llamado Periodo Intermedio Temprano de casi un milenio de duración hasta soo d.C. Es cuando surgen las culturas moche (o mochica) en la costa norte del Pacífico andino, y N azca, un poco más al sur. Se trata de civilizaciones agrícolas en toda forma, que cultivaban algodón, maíz, papa, calabaza, chile y coca (esta última para efectos rituales), y que practicaban exitosamente la pesca. El sitio de M oche, cerca de la desembocadura del río homónimo sobre el 0 céano Pacífico, muy cerca de la actual Trujillo, era toda una ciudad y muestra todavía restos de unas huacas del Sol y de la Luna, pirámides escalonadas no muy distintas y coetáneas de las de Teotihuacan. La huaca del Sol fue una de las mayores pirámides de adobe del Continente Americano, ya que medía $350 \mathrm{~m}$ por lado, si bien su altura apenas alcanzaba los $40 \mathrm{~m}$.

Por su parte, la cultura nazca dejó pocos vestigios de su arquitectura, pero en cambio perfeccionó las técnicas de la cultura precedente de Paracas, consistentes marcas, extensas planicies o pampas con líneas, bandas o figuras gigantescas que sólo se pueden apreciar desde el aire. Algunas son motivos geométricos 0 zoomorfos, presentes también en su cerámica. Esta singular manera de marcar simbólicamente el territorio es un ejemplo que no ha sido suficientemente aquilatado por los profesionales contemporáneos de la arquitectura de paisaje.

5. Rogger Ravines, "G aragay: un centre cérémoniel du Formatif", en M usées Royaux d'Art et d'H istoire, Inca-Perú, 3000Ans d'H istoire, Gent, Imschoot U itgevers, I990, pp. 132-I46.

6. M ichael Coe et al., op. cit., pp. I8o-I8I. 


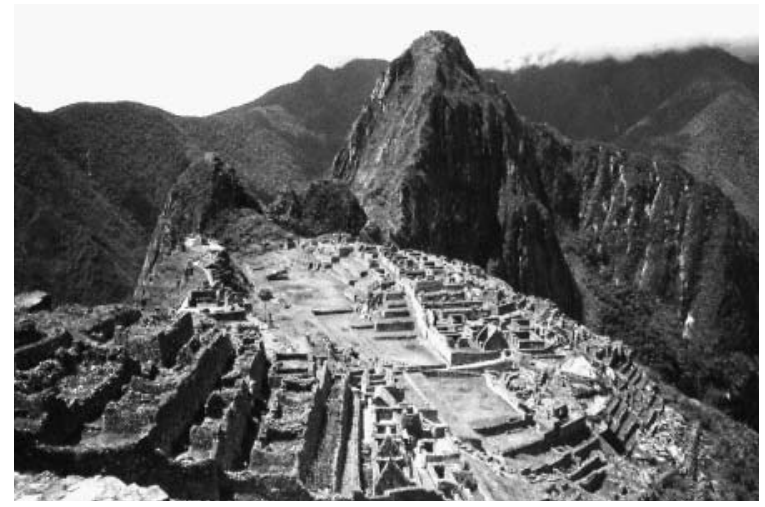

2. Ciudadela incaica de M achu Picchu, Perú, siglo xv. Foto: Alberto González Pozo.

El siguiente lapso es el H orizonte Intermedio, contemporáneo del Epiclásico mesoamericano, ya que se sitúa entre 500 y 900 d.C. D os ciudades-Estado del altiplano dominan a casi todas las demás en esta época: H uari al norte y Tiahuanaco al sur. Ambas traslapaban su esfera de influencia sobre el territorio en que había surgido la cultura nazca.

El sitio de Tiahuanaco (Bolivia) tuvo una ocupación que se remonta a I50o a.C. y permanece hasta izoo d.C., pero su esplendor ocurre en el H orizonte Intermedio. Era una isla de unos goo por soo $\mathrm{m}$ rodeada por canales que la conectaban con el lago Titicaca, situado a más de $4000 \mathrm{~m}$ sobre el nivel del mar. H oy está separada de sus márgenes y en sus vestigios arquitectónicos se advierte un sugerente juego dialéctico entre el montículo o pirámide principal en forma de $U$, la Akapana, ${ }^{7}$ y el conjunto de Kalasasaya, que es una plataforma con un gran patio hundido. Esta oposición entre patio hundido y montículo principal recuerda la que también existe en la acrópolis casi

7. La arqueóloga mexicana Linda M anzanilla opina que esa pirámide era una especie de "acto de conmemoración de la creación del mundo", por lo que su ubicación coincide con el eje del mismo. También observa la presencia de dos grupos de usuarios: sacerdotes cóndores y pumas, lo que explica algunas simetrías del conjunto, así como una coincidencia con dualismos iconográficos en sitios mesoamericanos donde se representan guerreros identificados con felinos 0 aves de presa, por ejemplo en Cacaxtla o en el Templo M ayor de Tenochtitlan. Cfr. Linda M anzanilla, Akapana, una pirámide en el centro del mundo, M éxico, UNAM, Instituto de Investigaciones Antropológicas, I992, pp. I07-Io9. 
contemporánea de M onte Albán, y obliga a preguntarnos sobre posibles intercambios o simples coincidencias entre ambas formas de concebir el espacio ritual, distantes más de $6000 \mathrm{~km}$ entre sí.

Al patio hundido de Kalasasaya se ingresa por dos marcos-portal simbólicos, uno de ellos la Puerta del Sol. La función simbólica que cumplía esa puerta no es muy distinta de algunos torii pétreos de la arquitectura hindú mucho después, pero su naturaleza construida es totalmente distinta, ya que el portal simbólico no está constituido por piezas sino que se trata de un monolito ricamente labrado de $4 \mathrm{~m}$ de ancho por 3 de alto con un vano al centro. Por otra parte, en las paredes o muros de contención del patio hundido, sobresalen las consabidas cabezas-clavas, un rasgo que proviene de la cultura Chavín, pero finamente interpretado. Tiahuanaco se encuentra ahora entre los sitios bolivianos en la lista del patrimonio mundial.

Las chullpas o torres funerarias cilíndricas de piedra o adobe son otra tipología interesante en el área de infuencia de Tiahuanaco. Se empleaban para depositar restos humanos en su cúspide para que los cóndores y otras aves carroñeras se encargaran de devorar los tejidos orgánicos, dejando limpios los esqueletos. Vestigios de estos interesantes edificios se encuentran en Sillustani y Cantamarca. ${ }^{8}$

Las relaciones entre los tiahuanacotas y su medio ambiente lacustre eran muy sabias: desarrollaron una técnica de camellones (parecida a las chinampas mesoamericanas) en los que podían practicar agricultura intensiva. $Y$ todavía hoy se advierte, en todas las laderas montañosas que rodean al extenso lago Titicaca, la labor de muchos siglos de construcción y mantenimiento de terrazas agrícolas en las que se evita la erosión y se aprovecha el agua pluvial al máximo. Siglos adelante, los incas heredaron y explotaron esas eco-técnicas.

$M$ ientras Tiahuanaco ejerció su influencia hacia el Sur, hasta la cañada de Humahuaca (Argentina), H uari, cerca del actual Ayacucho, inició una expansión incesante hacia la costa y el $\mathrm{N}$ orte. Sus realizaciones arquitectónicas son prácticas y utilitarias, como los conjuntos de Pikillakta y de Viracochapampa. Ambos cuentan con amplias plazas centrales y un sinnúmero de locales habitables y de almacenamiento rigurosamente zonificados e incluso modulados, y muestran claramente que su propósito era servir como centros

8. Sergio Purin, "Les civilisations du Pérou ancien”, en M usées Royaux d'Art et d'H istoire, op. cit., p. 32. También Kauffmann-D oig, op. cit., pp. 475-478. 


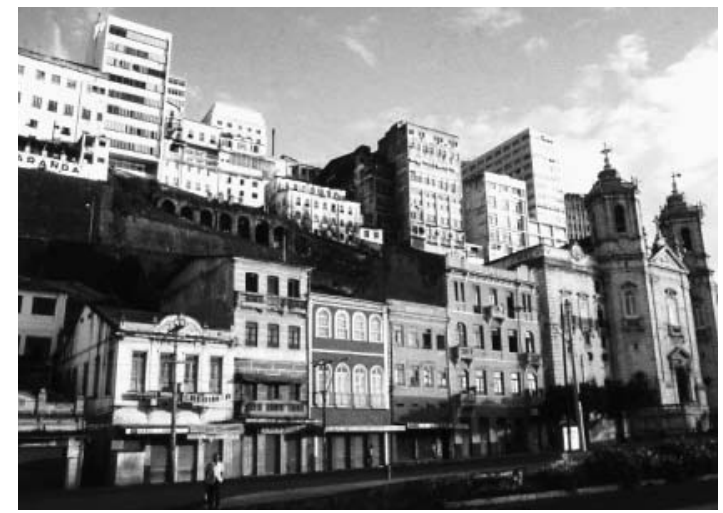

3. Salvador de Bahía, Brasil. Sectores alto y bajo.

Foto: Alberto González Pozo.

administrativos y para concentrar excedentes de la producción agropecuaria de regiones dominadas por ese incipiente imperio. ${ }^{9}$

\section{L as etapas finales de Sudamérica prehispánica}

$\mathrm{H}$ ay un Periodo Intermedio-Tardío que se limita a la costa peruana entre 900 y 1476 d.C. En ese lapso florecen dos culturas urbanas importantes: la primera duró hasta i35o y se limitó a la cuenca del río Lambayeque, del que toma su nombre, aunque también se conoce como cultura de Sicán. Sus principales centros urbanos fueron: primero, Batán $\mathrm{G}$ rande y, más tarde, $\mathrm{Ce}$ rro Purgatorio. Este último asentamiento, constituido por ciudadelas, rodea a un enorme promontorio pétreo. ${ }^{10}$ Esta tipología urbanística prefigura la siguiente etapa que se comenta a continuación.

Finalmente, la cultura de Sicán es sojuzgada como consecuencia del advenimiento y consolidación del imperio Chimú (o Chimor), que logró unificar bajo su dominio a multitud de cuencas de la vertiente occidental de los Andes. El urbanismo imperial de los chimú era de riguroso control social,

9. Denise Pozzi-Escot, “L'Empire Wari”, en M usées Royaux d'Art et d'H istoire, op. cit., pp. 196-20I.

Io. Kaufman-D oig, op. cit., pp. 40o-40I. 
a juzgar por la constitución de su capital Chan Chan, formada por diez ciudadelas contiguas y relativamente independientes. $\mathrm{No}$ se puede menos que reflexionar sobre las analogías entre esta estructura de la ciudad más extensa de Sudamérica precolombina y la de Teotihuacan, donde cada manzana era una vecindad corporativa cerrada, ${ }^{\text {II }}$ como tampoco pueden pasar inadvertidas sus semejanzas con las grandes capitales históricas de C hina: C hang'An y Pekín, donde también existieron grandes sectores urbanos separados entre sí. ${ }^{12} \mathrm{O}$ tros rasgos interesantes reflejan su estrecha relación con los rigores del medio ambiente: como que el litoral del Pacífico donde se ubica es desértico, la ciudad está totalmente construida con adobes y "tapias" (tramos de muros de tierra apisonada entre moldes). Incluso hay celosías y finas decoraciones arquitectónicas de grecas hechas con barro modelado. Por otra parte, subsisten vestigios de grandes estanques o cisternas donde se almacenaba agua necesaria para la supervivencia.

La importancia de $\mathrm{C}$ han $\mathrm{C}$ han corresponde a su rango actual de ejemplo del patrimonio cultural de la humanidad, pero hay muchos otros sitios de esa época que merecen analizarse y darse a conocer, como Pacachamac, cerca de Lima actual, ${ }^{13}$ y A purle. En realidad, Pacachamac era una ciudad-santuario y su origen es muy anterior al del imperio chimú, pero es en esta etapa cuando alcanza un esplendor y una veneración regional que se prolonga hasta la epoca incaica.

La tecnología del imperio chimú fue todavía más compleja. Sus miembros eran capaces de construir canales para conectar dos cuencas fluviales contiguas, siguiendo las curvas de nivel del terreno, sin que hoy día se logre comprender cómo lograron esta hazaña topográfica, carentes de los instrumentos que ahora empleamos. También construyeron carreteras y caminos que recorrían centenares de kilómetros, tecnología que luego heredaron a los incas, quienes los sojuzgaron.

Como los aztecas en M esoamérica, que se expandieron a partir de Tenochtitlan, los incas (I476-1534) multiplicaron rápidamente su dominio des-

II. Laurette Sejourné, Arquitectura y pintura en Teotihuacán, M éxico, Siglo XXI, I969.

I2. Jorge E. H ardoy, op. cit., p. 37I, observa atinadamente que "en ambas culturas fue costumbre dividir los distritos interiores de las ciudades mediante muros que con frecuencia eran no menos formidables que los exteriores".

I3. Ponciano Paredes Botoni, "Pacachamac", en Musées Royaux d'Art et d'H istoire, op. cit., pp. 178-195. 


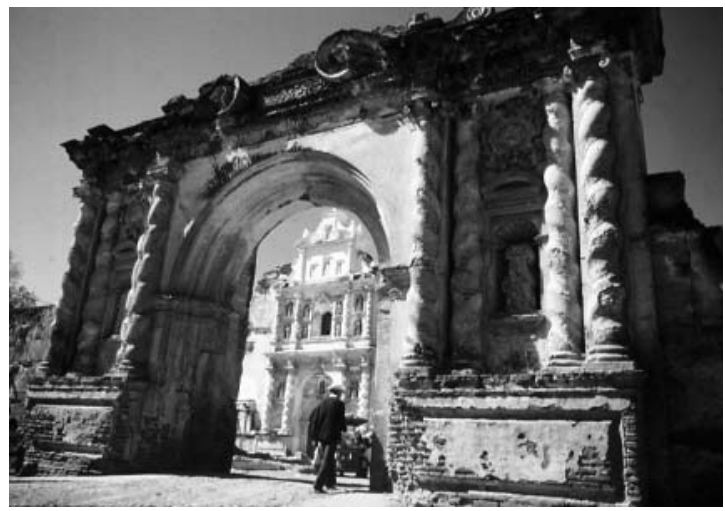

4. Portada atrial, La M erced, Antigua, Guatemala, siglos XviI-Xviır. Foto: Alberto González Pozo.

de la región del Cuzco sobre casi toda la zona andina en el último lapso de las culturas prehispánicas sudamericanas conocido como H orizonte Tardío. Ambas culturas, la azteca y la incaica, heredaron y acrecentaron el saber y las técnicas de los pueblos que les precedieron, pero dentro de una organización militarista e imperialista; en la cúspide de su poderío, ambas hicieron contacto con los españoles y sucumbieron ante ellos en sendas guerras. H asta ahí las analogías, porque las diferencias entre sus respectivos urbanismos y arquitecturas son mayores que en los periodos precedentes. Si los aztecas conservaron las pirámides como edificios culminantes de sus centros ceremoniales (ciertamente con menor escala que las de los horizontes clásico y epiclásico), los incas evitaron concentrar tanto esfuerzo edificatorio en grandes montículos y lo distribuyeron mejor entre diversas obras con importantes funciones utilitarias: terrazas agrícolas y caminos, ${ }^{14}$ pero también fortificaciones, espacios abiertos y cubiertos donde se concentraban los excedentes de la producción, centros de control, palacios, plazas y viviendas. El equilibrio y la diversidad de programas utilitarios, así como el control social que se advierte en las disposiciones urbanísticas reflejan una cultura que algunos han caracterizado como "socialista". ${ }^{\text {Is }}$

I4. Los incas llegaron a acumular cerca de 40 ooo kilómetros de caminos, según M ichael Coe et al., op. cit., p. 20 .

I5. L ouis Badouin, D er Sozialistische Staat der Inka, Rowohlt H amburg, 1956. 
Su urbanismo ofrece algunas analogías con la antigüedad helénica. En Cuzco, por ejemplo, la acrópolis donde se ubica la fortaleza de Sacsahuamán, con su triple muralla, domina a la capital incaica. ${ }^{6}$ El uso de megalitos de más de 3 metros de al tura para levantar ese sistema defensivo no era muy diferente del que emplearon los micénicos en sus propias acrópolis, pero las técnicas empleadas para cortarlos y armarlos fueron más sofisticadas. A juzgar por estimaciones recientes, Cuzco prehispánico llegó a constituir una verdadera aglomeración metropolitana donde convivían cerca de 300 ooo habitantes. ${ }^{17} \mathrm{En}$ su planimetría urbana hay, según otros autores, un fascinante zoomorfismo: su perímetro se asemeja al perfil de un puma americano, donde la cabeza corresponde a la fortaleza, mientras que el cuerpo del felino sería el resto de la ciudad. ${ }^{18}$

O llantaytambo es otro ejemplo de emplazamiento extremo que se aferra con sus garras pétreas a las empinadas pendientes andinas. $\mathrm{H}$ oy día, un poblado colonial homónimo ocupa la misma extensión y partes de la traza que tuvo la ciudad prehispánica. ${ }^{19}$ Lo destacable es que el enorme esfuerzo de construir ese asentamiento es mínimo comparado con el que se requirió para terracear extensas zonas en sus alrededores, haciéndolas cultivables. Lo mismo ocurre en M achu Picchu, la remota ciudad entre las nubes, situada dos kilómetros por encima del río U rubamba. Al parecer, los españoles no llegaron a conocer esa ciudadela que ahora es uno de los sitios arqueológicos más importantes del Continente Americano, inscrito en la lista del patrimonio mundial.

Pero las culturas andinas, por más variadas que hayan sido en cuanto a regiones y épocas, no son más que parte de todas las culturas precolombinas centro y sudamericanas. $\mathrm{H}$ ay regiones sudamericanas, más apartadas del núcleo andino, donde se observa su influencia, como ocurre en la sabana de Bogotá,

I6. Heinrich U bbelöhde Doering, Kulturen Alt-Perus, Tubinga, Verlag Ernst Wasmuth, I966, pp. 193-195.

17. Jean-François Bouchard, “L'architecture Inca”, en M usées Royaux d'Art et d'H istoire, op. cit., p. 484, indica que en el núcleo central vivían de 15000 a 20000 habitantes, otros 500000 más en barrios periféricos, de 50000 a ııо ooo en zonas suburbanas y 1 Io 000 o más en zonas rurales circunvecinas.

I8. Teresa Gisbert, H istoria de la arquitectura y el urbanismo precolombino en Bolivia, M éxico, Instituto Panamericano de G eografía e H istoria, I980, t. I.

19. H einrich U bbelöhde D oering, op. cit., pp. 249-252. 
5. Iglesia de San Francisco, O uro Preto,

Brasil, siglo xviII. Foto: Alberto González Pozo.

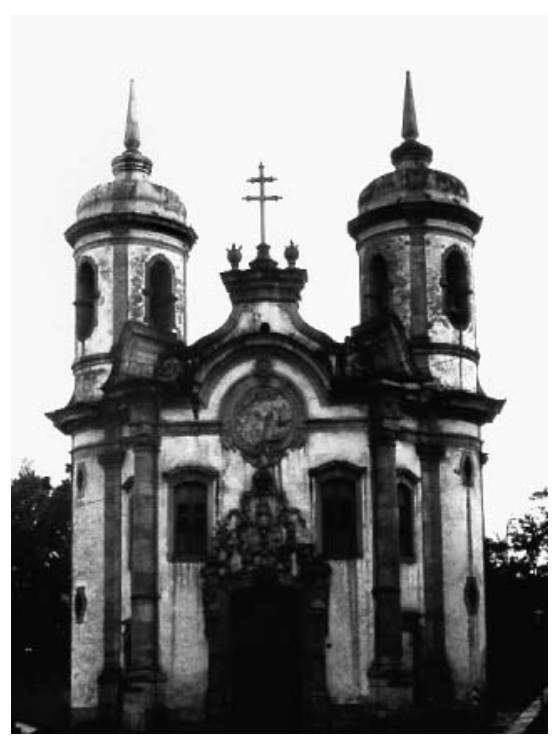

poblada por muiscas antes del contacto con los españoles. ${ }^{20}$ D esgraciadamente, son muchas todavía las lagunas de conocimiento que tenemos sobre los antiguos pueblos taínos, arahuacos y caribes que florecieron en las grandes islas del Golfo de M éxico y el M ar Caribe. Porque precisamente el área de Centroamérica y el $C$ aribe es donde pudieron haberse registrado contactos entre los dos grandes focos culturales de M esoamérica y Sudamérica precolombinas. Son cuestiones que algún día habrán de explicarse mejor; cabos sueltos que deben retomarse si se quiere tener completo el panorama de la evolución de la arquitectura y el urbanismo hasta antes de la dominación hispano-portuguesa en América.

20. Silvia Arango se refiere a un asentamiento a base de recintos cercados que podría ser influencia de Chan Chan, sólo que, en vez de muros de adobe y tapial, las cercas que dividen las ciudadelas son de madera, y, en vez de techos planos de azotea, las cubiertas eran piramidales de madera y palma. C fr. Silvia Arango, Historia de la arquitectura en Colombia, Bogotá, Universidad Nacional de Colombia, 1989, pp. 30-35. 
Los primeros asentamientos y edificaciones de las colonias hispano-portuguesas

$\mathrm{H}$ ace mucho que ha sido superada la noción de que las exploraciones marítimas, los descubrimientos sucesivos y las guerras de conquista emprendidas por españoles y portugueses y la instauración de gobiernos coloniales durante todo el siglo xvi prepararon el terreno para sustituir arquitecturas y urbanismos indígenas por edificios y ciudades semejantes a los de la península ibérica de esa época. El fenómeno es mucho más complejo que eso: en primer lugar, porque las persistencias indígenas fueron muy fuertes en algunas regiones americanas y dejaron su huella en inmuebles y asentamientos levantados por los conquistadores; en segundo, porque las propias culturas española y portuguesa del siglo xvi formaban un racimo integrado por su pasado medieval, su herencia islámica y su muy reciente incorporación al Renacimiento; y en tercer término, porque hay muchos ejemplos que demuestran que hubo grandes dosis de ingenio, de adaptación y de inventiva en el trazo de los asentamientos iberoamericanos y en las soluciones arquitectónicas del Nuevo Mundo. Todo esto se prolongó hasta las primeras décadas del siglo xIx, cuando casi toda Iberoamérica comenzó a independizarse.

En esos tres siglos hay bastantes semejanzas entre los urbanismos y las arquitecturas de las distintas regiones americanas. Pero no son pocas las diferencias: la diversidad de ambientes, la pertenencia a al guna de las dos potencias coloniales y, por último, la mayor o menor presencia de las culturas indígenas ancestrales, con todo y sus antiguas tecnologías urbanísticas y constructivas.

Así como la traza española de M éxico-Tenochtitlan en I524-I527 no pudo ignorar el trazado previo de calzadas y canales de la metrópolis azteca, en el Cuzco virreinal tampoco se pudo prescindir de los sólidos muros pétreos de la capital incaica. M uchas casas y algunas de las iglesias virreinales cuzqueñas son aprovechamientos de preexistencias para reutilizar a la ciudad destruida. ${ }^{21}$ El caso de Quito también ejemplifica ese mismo pragmatismo con el que los españoles, más que comenzar a trazar las ciudades ex-novo, tomaron muy en cuenta la ordenación territorial y las trazas preexistentes. ${ }^{22}$

2I. Pedro. A. Belaunde, "Cusco", en Centros históricos. América Latina, Bogotá, Junta de Andalucía-Universidad de los Andes-Escala Colombia, 1990.

22. Peñaherrera M ateus, "Evolución del trazado urbano de Q uito, desde I500 a I922", en Sociedad Ecuatoriana de Investigaciones H istóricas y G eográficas, M emoria núm. 2, 1991 1992, Q uito, 1993. 


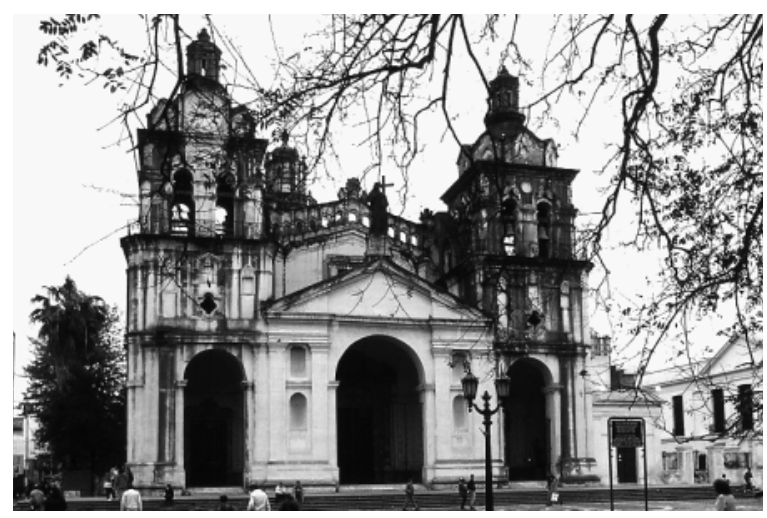

6. Catedral de Córdoba, Argentina, siglos XviI-XviII. Foto: Alberto González Pozo.

Si se rastrean algunas supervivencias urbanísticas de la Edad M edia, podría mencionarse al patrón característico de lotificación medieval que se adoptó en Panamá, una de las primeras fundaciones españolas del Continente (I519), con predios angostos y alargados. ${ }^{23}$ Las manzanas y lotes cuadrados vendrían después: en Tepeaca lo mismo que en Buenos Aires, en Córdoba ${ }^{24}$ 0 en $M$ endoza (Argentina), cuando ya se habían instituido las famosas $0 \mathrm{r}$ denanzas atribuidas a Felipe II. Antes hubo otros experimentos: manzanas rectangulares con lotes cuadrados en $M$ éxico y en Puebla, o manzanas cuadradas con lotes rectangulares en 0 axaca. Sin duda, en la primera mitad del siglo xvi hubo mucha difusión de modelos europeos, pero también se experimentó y se inventaron nuevas soluciones.

Por ejemplo, el atrio y las capillas posas o las capillas de humilladero frente a las iglesias de las órdenes mendicantes no se dieron exclusivamente en N ueva España: también los encontramos en Perú o Bolivia, incluso sobrepuestos a antiguas plataformas precolombinas, como el Santuario de Copacabana, Bolivia, cerca del lago Titicaca o el Santuario de M anquirí, cerca de

23. M anuel Castillero Calvo, La vivienda colonial en Panamá, Panamá, Shell, 1995.

24. M aría Elena Foglia et al., La cuadrícula en el desarrollo de la ciudad hispanoamericana. El caso de Córdoba, 15/3 1810, Córdoba, Universidad N acional de Córdoba-Facultad de Arquitectura y U rbanismo, 1987. 
DOI: http://dx.doi.org/10.22201/iie.18703062e.2004.85.2412

IOO

ALBERTO GONZÁLEZ POZO

Potosí, donde todo el recinto religioso, incluyendo el atrio, se levanta sobre una antigua huaca prehispánica. ${ }^{25}$

Las distintas estrategias de expansión territorial y control social empleadas por españoles y portugueses tienen un punto importante de convergencia en la evangelización de extensas regiones indígenas a cargo de los jesuitas. Los ignacianos no comenzaron tan pronto como las órdenes mendicantes en M éxico, pero supieron de sus experiencias evangelizadoras y se inspiraron en ellas para sus propias misiones, verdaderas reducciones que les permitieron concentrar grupos indígenas entre 5000 y 20000 habitantes en distintas regiones periféricas de la Amazonia, formando repúblicas de indios en territorios que ahora pertenecen a Bolivia, Argentina, Paraguay y Brasil. En esos asentamientos, reinterpretaron el patrón de asentamiento de grupos aborígenes, como los guaraníes, que constaban de cuatro o más ogas plurifamiliares de materiales perecederos (cada una habitada por 80 a 200 personas) dispuestas en torno a un espacio central. ${ }^{26}$ En la versión jesuita, en vez de casas comunes hay largas crujías de material duradero (piedra o ladrillo) divididas en cuartos para cada familia, accesibles desde un portal común. La misión y sus dependencias (iglesia, claustro o claustros y huerta) dominan uno de los lados de la plaza, mientras que las crujías habitacionales de los indios rodean los otros tres lados. Fue una política de poblamiento exitosa que, por cierto, les permitió exportar ese modelo a un ámbito ecológicamente distinto en la Baja y la Alta California. ${ }^{27}$

En esos pueblos-misiones sudamericanos, la densidad del asentamiento y su riguroso orden geométrico dan cuenta del equivalente orden social y moral perseguido por los ignacianos. Pero pronto entraron en conflicto con los intereses de otros colonos españoles y portugueses (particularmente los bandei rantes paulistas que trataron siempre de esclavizar a los indios) y ya para mediados del siglo xviı se encontraban en una situación crítica que finalmente se resolvió con la expulsión de los jesuitas de todos los dominios españoles. El abandono y posterior ruina de las reducciones no se hizo espe-

25. José de M esa y Teresa Gisbert, "Arquitectura, pintura y escultura", en varios autores, Potoś, patrimonio cultural dela humanidad, La Paz, Compañía M inera del Sur, I988, p. I36.

26. Salvador Cabral et al., "M edio natural y cultura aborigen", en Icomos-Unesco, Las misiones jesuíticas del Guayrá, Buenos Aires, M anrique Zago, I993, pp. 31-32.

27. M iguel M essmacher, La búsqueda del signo de dios. O cupación jesuita de la Baja California, M éxico, Fondo de Cultura Económica, 1997. 
7. Portada doméstica, Potosí, Bolivia, siglo xviII. Foto: Alberto González Pozo.

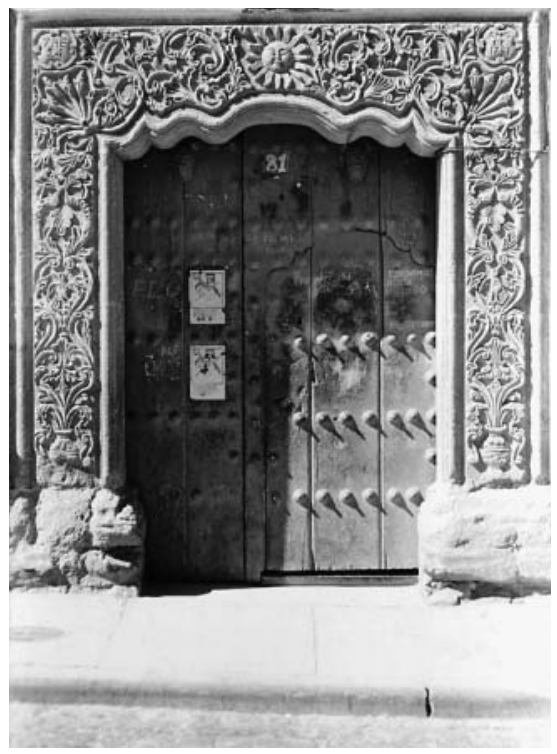

rar. H oy, esos restos de las misiones jesuíticas del Guayrá ${ }^{28}$ o las de M ojos y Chiquitos forman parte del patrimonio cultural de la humanidad.

Al parecer, la tipología de corredores-portal de las misiones, donde la vida doméstica se prolonga en un espacio social, influyó sobre las respectivas arquitecturas regionales, por ejemplo, en algunos templos perípteros como en Yaguarón (Paraguay) o en asentamientos que florecieron en el siglo xviII, como Santa Cruz o Trinidad (Bolivia) y otros que desgraciadamente han desaparecido, donde los corredores o portales rodean total mente a las manzanas, imprimiéndole a la ciudad una singular imagen urbana. ${ }^{29}$

\section{L os puertos y sus sistemas defensivos}

M uchas de las primeras ciudades portuarias del siglo xvi y sus fortificaciones han desaparecido o evolucionado, como la primera Panamá y Portobelo en el

28. Jorge O . G azaneo, "G eopolítica de las misiones”, y Alberto de Paula, “La arquitectura de las misiones del Guayrá", en icomos-Unesco, op. cit., pp. 75-15I.

29. Ramón Gutiérrez, Arquitectura y urbanismo en Iberoamérica, M adrid, Cátedra, I992, pp. 2I0-219. En M éxico tenemos un caso semejante en T lacotal pan, pero sin influencia misional. 
IO2

Istmo de C entroamérica, Trujillo en Perú o la primera Buenos Aires sobre el río de La Plata. H oy, el fuerte de San Felipe en la Laguna de Izabal, Guatemala, accesible desde el $M$ ar $C$ aribe por un río navegable para las embarcaciones de aquellas épocas, puede parecer débil defensa ante posibles incursiones si se le compara con los poderosos sistemas defensivos posteriores en La H abana y Santiago (Cuba), en San Juan (Puerto Rico), , ${ }^{\circ}$ o Cartagena de Indias (Colombia)..$^{3 \mathrm{~L}} \mathrm{La}$ evolución tecnológica de las armas de fuego a partir del siglo xvi influyó, sin duda, en las previsiones defensivas que tomaron en América tanto España como Portugal, no tanto para protegerse de los naturales sino de las incursiones de piratas o corsarios de nuevas potencias en la escena europea. Sin embargo, deben tomarse en cuenta los distintos grados de vulnerabilidad de estos sitios fortificados según el volumen de riquezas o recursos que protegían. D ependiendo del riesgo, las ciudades podían incluso prescindir de murallas y limitar sus defensas a la presencia de una buena fortal eza militar contigua o central, como en la segunda Buenos Aires.

Brasil, ocupado en buena parte por la gran cuenca selvática del Amazonas, limitó al principio el proceso de ocupación de su territorio a las zonas costeras atlánticas y territorios inmediatos. De hecho, sus principales ciudades hasta el siglo xvir fueron marítimas, como Salvador de Bahía, O linda y Río de Janeiro, o muy cercanas al litoral, como São Paulo. Salvador se fundó en I549 como capital de las posesiones portuguesas en América, con un primer núcleo urbano de traza más o menos regular que ya para el siglo xvir había crecido al doble. La ciudad estaba unos $60 \mathrm{~m}$ sobre el nivel del puerto, lo que obligó desde un principio, aparte de construir las consabidas fortificaciones para defender el sitio, a encontrar la mejor forma de subir las mercaderías de la parte baja de la ciudad a la parte alta. Para ello se dispuso una empinada rampa: el guindaste, por donde la carga se izaba literalmente con ayuda de poleas sobre grandes ruedas de madera. ${ }^{22}$ Esta función mecánica especializada dejó su huella sobre la evolución posterior del mismo sitio, ya que en el siglo xx surgió ahí un elevador municipal que aún funciona, ahora

30. Ramón Gutiérrez, “Espacio y fortificación en América”, en Junta de Andalucía, Andalucía en América: el legado de ultramar, Barcelona-M adrid, Lunwerg, I995, pp. I45-i6I.

3I. José Salazar Ferro et al., Patrimonio urbano en Colombia, za ed., Santafé de Bogotá, Subdirección de Patrimonio-Colcultura, 1997, p. 52.

32. N estor Goulart Reis, Evoluçao U rbana do Brasil 15001720, 2a ed., São Paulo, Pini, 200I, pp. I44-I49. 


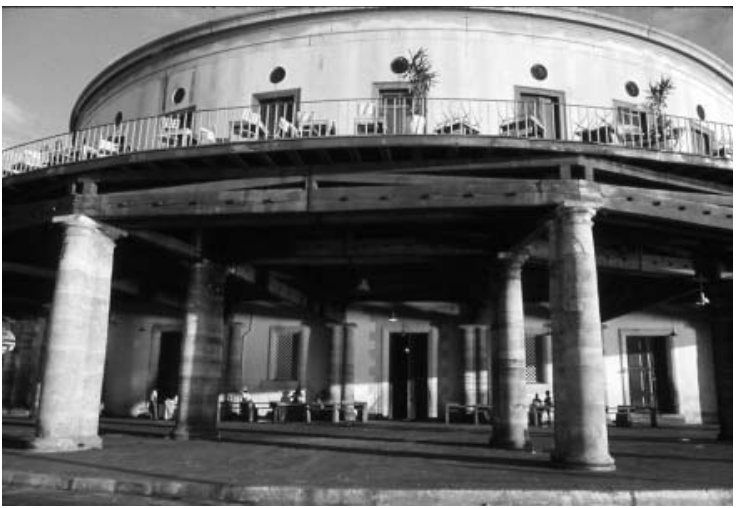

8. M ercado anexo, alhóndiga de Salvador de Bahía, siglo xix. Foto: Alberto González Pozo.

en beneficio de los habitantes que ascienden o descienden entre las ciudades baja y alta.

Los enclaves marítimos portugueses compartieron un mismo riesgo con sus homólogos españoles: podían ser atacados e incluso destruidos por corsarios o piratas, como ocurrió con la primera Panamá (o Panamá V iejo), incendiada en I671 y reubicada a partir de I673 en el actual centro histórico, unos pocos kilómetros al poniente. ${ }^{33}$

Entre los siglos xvi y xviII, algunos de esos puertos y otros nuevos cambiaron de manos (incluso varias veces) entre las potencias colonizadoras y, en consecuencia, recibieron variados influjos de la cultura urbanística y arquitectónica europea. El caso de Recife es una muestra de ello: fundado en un arrecife que explica su topónimo, estuvo bajo dominio holandés entre i620 y I660, hasta que fue recuperado por la corona portuguesa. Para entonces, los holandeses ya habían dejado importantes huellas edificadas de su presencia; entre ellas, la primera sinagoga en el Continente Americano, cuyos restos aún se conservan.

33. Alfredo Castillero Calvo, Arquitectura, urbanismo y sociedad. La vivienda colonial en Panamá. Historia de un sueño, Panamá, Biblioteca Cultural Shell, I994. 
IO4

Los enclaves productivos

La diversificación de las economías coloniales fue dándoles una vocación a muchos otros asentamientos de tierra adentro. Los jesuitas, por ejemplo, ubicaron importantes estancias de producción agropecuaria de imponente arquitectura en Santa Catalina, cerca de Córdoba (Argentina). ${ }^{34}$

La producción azucarera también cobró importancia desde el siglo xvi en los territorios americanos que apenas comenzaban a ocupar españoles y portugueses. Pero pronto se plantearon las limitaciones de explotarlos con mano de obra indígena. Por eso, ya en el siglo xvir se inició el tráfico de esclavos africanos, que se consideraban más apropiados para este tipo de labor. Los ingenios en el área del Caribe y en Brasil deben su productividad a esa explotación étnica, pero han dejado pocos vestigios de sus edificaciones. En cambio, las minas en Potosí (donde se explotaba a los indios mediante el sistema de la mita ) obligaron a un urbanismo adaptado a esas funciones, con interesantes vestigios de haciendas circunvecinas de beneficio minero, con molinos de trituración movidos por energía hidráulica y una espléndida casa de acuñación de moneda. ${ }^{35}$ En Brasil también hubo enclaves mineros importantes, sobre todo a raíz del descubrimiento de oro y diamantes a fines del siglo xvi en la zona de M inas G erais.

Sin embargo, ya en la segunda mitad del siglo xviri comienza a sentirse el influjo del nuevo orden borbónico que prevalecía en Europa. Las nuevas fundaciones urbanas adquieren entonces una lógica que llama la atención, como en San José de M acapá y N ueva M azagão. Ambas ciudades jugaban un papel importante en el sistema regional dominado por una empresa monopólica creada para explorar y explotar los recursos de esa inmensa zona norteña del Brasil. La traza de San José de M acapá, a orillas del Amazonas, Ilama la atención por su rigurosa retícula ortogonal, sus lotes angostos y alargados, y sus dos generosas plazas centrales: una para el mercado y otra para la administración municipal y la iglesia. En cambio, en Nueva M azagão, la traza ortogonal se interrumpe sólo cuando los bajos o el curso de los afluentes del

34. Carlos M oreno, Españoles y criollos, largas historias de amores y desamores, 4. De las vie jas tapias y ladrillos, Buenos Aires, Centro para la Conservación del Patrimonio U rbano y Rural, 1995, p. 25.

35. Juan Fernández, "La minería colonial”, en varios autores, Potosí, patrimonio cultural de la humanidad, La Paz, Compañía M inera del Sur, I988, pp. 245-25I. 
9. Teatro, Q uetzaltenango, Guatemala, siglos xix-xx. Foto: Alberto González Pozo.

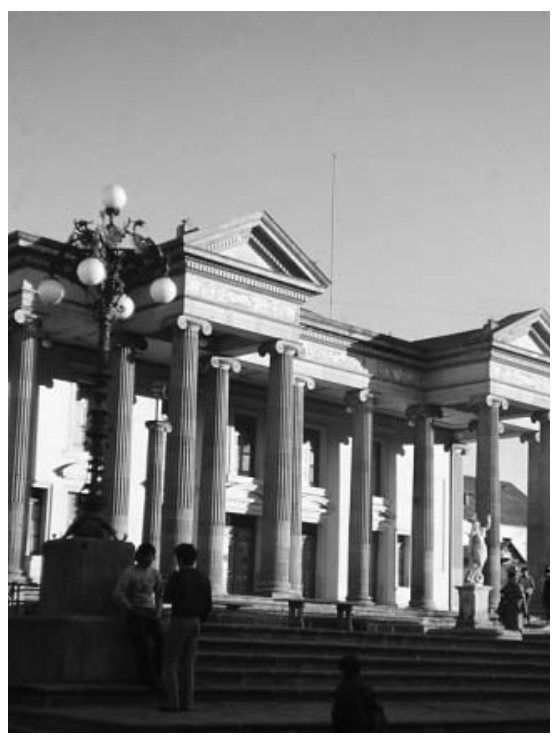

río Mutucá lo impedían, ${ }^{36}$ algo que también hizo Le Corbusier casi dos siglos después en su diseño urbano para C handigarh.

\section{La arquitectura religiosa}

Q uizá porque la iglesia era la presencia más importante en el espacio edificado de las ciudades coloniales iberoamericanas, recibió mucha más atención de autoridades eclesiásticas y civiles y tiende a una mayor uniformidad, sin dejar de registrar, claro está, los cambios del renacimiento al manierismo y de éste al barroco. Pero también son discernibles algunas diferencias que provienen de la propia península ibérica y se acentúan en América. El manierismo y el barroco portugueses ya se distinguían claramente de ejemplos coetáneos españoles en el gusto de los primeros por delinear las aristas de la arquitectura (sobre todo en los exteriores) mediante un lenguaje de pilastras y cornisamento donde la piedra expuesta luce más oscura, contrastando con

36. Roberta M arx N elson, N ovasVilas para o Brasil-Colonia. Planejamento Espacial eSocial no Século XVIII, Brasilia, ciord (C entro Integrado de O rdenamento Territorial)-Alva, I997. 
los paramentos enjarrados en blanco. Es como un retorno al mismo recurso empleado por Brunelleschi y Francesco di Giorgio sobre todo en interiores de iglesias renacentistas del siglo xv. Esta peculiar forma de dibujar los contornos de la arquitectura pasó a Portugal y luego a Brasil, donde tenemos varios ejemplos notables de los siglos xviı y xviı en Río de Janeiro, Salvador de Bahía, O linda, O uro Preto y Congonhas.

Todavía no está claro por qué el barroco berniniano o borrominiano, ese barroco de espacios interiores ovales y exteriores donde alternan superficies cóncavas y convexas, no prendió del todo en España y mucho menos en sus dominios americanos. $\mathrm{H}$ ay, ciertamente, manifestaciones tardías del siglo xviII, como la capilla del Pocito en el Santuario de Guadalupe en M éxico, la portada con calles laterales cóncavas de la catedral de La H abana, ${ }^{37}$ o el interesante claustro de novicias en el convento de monjas carmelitas en Antigua (G uatemala), donde las celdas semejan pétalos en torno a un patio circular..$^{8}$ Brasil aceptó con más naturalidad las tipologías espaciales barrocas, como en las iglesias de San Francisco o del Rosario de los N egros, 0 uro Preto, lo mismo que otros rasgos del barroco transalpino (suizo, alemán) como algunos chapiteles lobulados que rematan varios campanarios en Salvador de Bahía 0 en Río.

Las portadas fueron otro de los sitios escogidos por el barroco religioso hispanoamericano para concentrar ahí todos sus mensajes. Ahí se depositaron puntualmente todas las influencias externas y endógenas: desde el plateresco hasta el neoclásico; desde la omnipresencia de los mensajes iconológicos europeos hasta la interpretación ingenua de los artesanos indígenas que las levantaron. Todo se combinó y produjo ejemplos notables, ya fueran sobrios como las portadas de las catedrales de Cuzco o de Ayacucho, o de San Agustín, también en Ayacucho (Perú); o bien más complejos e imaginativos como en las catedrales de Córdoba (Argentina) y Lima (Perú), o en la iglesia de La Compañía en Q uito (Ecuador), provista de las mejores columnas salomónicas de toda América. Y hubo, claro está, portadas barrocas exuberantes como las de las iglesias de La M erced en Lima, de La C ompañía en Arequipa y de San Francisco en Cajamarca (Perú) o de La M erced en Anti-

37. Joaquín Weiss, La arquitectura colonial cubana. Siglo XVIII, La H abana, Letras Cubanas, 1979, pp. 74-76.

38. Ramón Gutiérrez, op. cit., 1992. 
Io. Lavadero público municipal, Totonicapan, Guatemala, siglo xix. Foto: Alberto González Pozo.

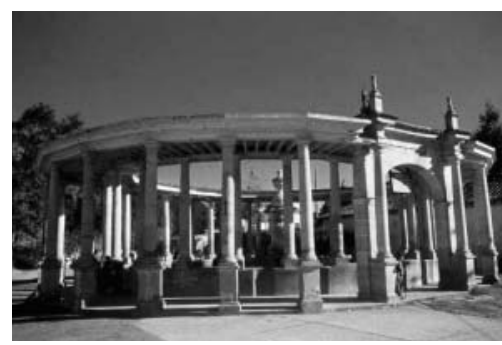

gua (Guatemala). 0 también, templos de pequeña magnitud pero de gran valía estética como los San Lorenzo y San Bernardo en Potosí (Bolivia). ${ }^{39}$

\section{La vivienda colonial latinoamericana}

Uno de los campos de estudio más interesantes en la arquitectura colonial de Centroamérica, Sudamérica y el Caribe es la vivienda, porque es el género que normalmente agrupa más de $90 \% 095 \%$ de las edificaciones que se levantaban en cada pueblo, villa o ciudad. No obstante, en la mayoría de historias de la arquitectura la atención se centra casi exclusivamente en los templos y los principales edificios públicos. Afortunadamente, esa visión estrecha ha comenzado a cambiar y ahora hay cada vez más autores que se ocupan más directamente de este importante tema. Castillero Calvo, por ejemplo, $4^{\circ} \mathrm{de}$ tecta viviendas urbanas típicas del siglo xviri en la N ueva Panamá, constituidas por una crujía de dos o tres niveles al frente del lote, donde se ubicaban la tienda y la vivienda de sus propietarios, una crujía lateral intermedia de un solo nivel y abierta a un patio con el pozo, donde estaban la cocina y el espacio para comer, todo en torno al fogón y la chimenea que sobresalía por encima de esa parte del edificio, mientras que al fondo del predio se erigía una crujía destinada a la servidumbre, que tenía acceso independiente por una calle de servicio.

39. José de M esa y Teresa G isbert, op. cit., pp. I54-I55. Ambos autores opinan que “la obra capital de la arquitectura potosina en cuanto a decoración es la portada de San Lorenzo, construida entre 1743 y $1744 "$.

40. Alfredo C astillero C alvo, Arquitectura, urbanismo y sociedad: la vivienda colonial en Panamá, historia de un sueño, Panamá, Biblioteca Cultural Shell, I994. 
IO8

La cocina también fue parte importante de las viviendas en Antigua (Guatemala), a juzgar por las notables chimeneas que se elevan por encima del fogón del hogar en esa ciudad. D esde la calle, algunas parecen más bien cupulines de capilla doméstica que chimeneas propiamente dichas.

Al analizar la vivienda urbana colonial, investigadores colombianos prefieren partir de un análisis tipológico de las trazas urbanas para pasar inmediatamente al de las parcelaciones, y de ahí a todas las posibilidades que los distintos tipos de lote ofrecían para la implantación de las viviendas, desde las más grandes, con dos o más patios rodeados por crujías, hasta las más modestas, formadas por soluciones tipológicas de dos crujías formando lo que en M éxico conocemos como una alcayata, o incluso por una sola crujía con un patio trasero exterior. ${ }^{4}{ }^{1}$ Por su parte, Covo Torres analiza las tipologías distributivas y constructivas más importantes de Cartagena de Indias, Colombia, presentándolas con dibujos caricaturizados, con el estilo de Eduardo del Río Rius que conocemos en M éxico. Gracias a ese recurso tienen información básica bastante clara y fácilmente comprensible, lo que no impide al autor llegar a detalles precisos sobre la carpintería de techumbres y balcones, incluyendo los tipos de ensamble más empleados. ${ }^{42}$

El aspecto de estas casas y su lógica constructiva deben mucho, sin duda, a la tradición andaluza, como también se advierte en otro rasgo que aparece una y otra vez en ciudades sudamericanas: el alto de madera, espacio habitable en el piso superior que toma la forma de balcón techado, todo de madera, abierto en ciudades cálidas y húmedas (como en Cartagena, en Puerto Cabello43 0 en La Habana) ${ }^{44} 0$ bien cerrado por celosías 0 vidrieras que aparece en climas secos o fríos (en Lima lo mismo que en Sucre o en Potosí). Algunos de estos bal cones limeños, como los de la casa Torre Tagle, son francamente moriscos. 45

Los altos de madera eran una forma distinta y más económica de resolver los mismos espacios que se obtenían con loggias altas, de arcadas a la manera renacentista, como las que tuvieron los palacios de Colón en Santo D omin-

4I. José Sal azar Ferro et al., op. cit., 1997.

42. Javier C ovo Torres, La casa colonial cartagenera, Bogotá, El Áncora, 1996.

43. Graciano Gasparini, Venezuela: monumentos históricos y arqueológi cos, M éxico, Instituto Panamericano de G eografía e H istoria, I966, p. 2I.

44. Joaquín E. Weiss, op. cit., i979.

45. Ramón Gutérrez, op. cit., pp. 173-175. 
II. Palacio de las Aguas Corrientes, gran cisterna municipal de Buenos Aires con fachada neorrenacentista, fines del siglo xix. Foto: Alberto González Pozo.

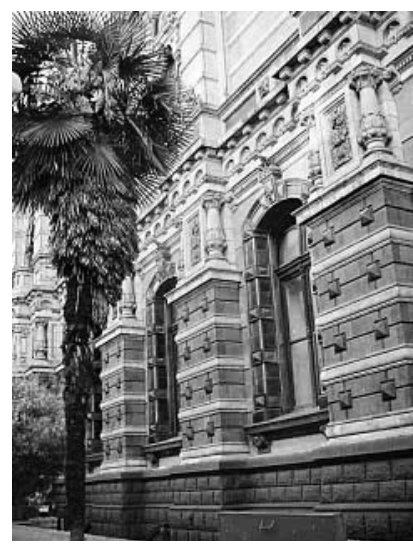

go y de Cortés en Cuernavaca. Esta útima tipología del piano nobile no desapareció del todo, especialmente en el Caribe, donde la encontramos todavía en el siglo xvin en casas burguesas o señoriales en Panamá o en La H abana.

Los patios de las casas son el corazón de la arquitectura doméstica. M uchos cumplen aún con susfunciones originales como en Coro o en LaVela, Venezuela, llenos de árboles, flores y animales domésticos, con sus frescas galerías donde transcurrela vida familiar. ${ }^{66} \mathrm{~A}$ primera vista, todos los patios son semejantes. Sus variantes se refieren a la forma en que están resueltos sus peristilos, ya sea con apoyos de piedra o ladrillo y arcadas, o bien, más frecuentemente, con columnas y dinteles de madera. Sin embargo, en Bolivia aparece ocasionalmente una tipología distinta en casas de dos niveles, como la C asa D iez de M edina en La Paz (actual M useo $\mathrm{N}$ acional de Arte), donde la escalera principal del inmue bleocupa por completo uno de los lados del primer patio. ${ }^{47}$

\section{Los materiales y sistemas constructivos de las colonias}

Las arquitecturas coloniales también reflejan la disponibilidad de recursos materiales y mano de obra en cada región. Por eso, independientemente de

46. Ana M aría Reyes, Coro y La Vela: la defensa de un patrimonio, Coro, Fundación Juventud y Cambio, 1996.

47. Este rasgo se prolonga hasta el siglo xix, por ejemplo en el asilo de ancianas de la calle Yanacocha, La Paz. Cfr. Teresa Gisbert, op. cit., vol. 2, M éxico, Instituto Panamericano de Geografía e H istoria, 199I, pp. I48, I53 y I89. 
los estilos que van sucediéndose durante los siglos coloniales y republicanos, vemos reflejado el medio ambiente en cada arquitectura local: desde las robustas mamposterías pétreas de la iglesias de Barichara en Santander 0 de M onguí en Boyacá (ambas en el altiplano colombiano) hasta catedrales levantadas con muros de adobe en $\mathrm{C}$ oro (Venezuela), ${ }^{8}$ de bajareque en Cuenca (Ecuador) o de ladrillo en Santa Cruz (Bolivia).

En la América colonial también se usaron muchas formas constructivas mudéjares, sobre todo en los caballetes de madera que soportaban tejados de iglesias y de arquitectura civil. Es un rasgo que casi desapareció en N ueva España a partir del siglo xviI, cuando muchos tejados se sustituyeron por bóvedas de mampostería, pero que subsiste todavía en el Caribe, desde Cuba hasta Venezuela; y en gran parte de Sudamérica, desde la costa atlántica de Brasil hasta la zona andina en Ecuador, Perú, Bolivia y el norte argentino. EI sistema básico era el caballete de par y nudillo de madera a la usanza mudéjar. Lo que varía son los refuerzos adicionales (como tirantes de madera ligando a las columnas) o la presencia agregada de artesonados. 49

0 tra influencia indirecta de la construcción mudéjar transportada a formas renacentistas o barrocas la encontramos en el empleo de los azulejos, sobre todo en Brasil, donde su profusión y calidad es sobresaliente, lo mismo en rodapiés de iglesias en Olinda que en lugares públicos en Salvador de Bahía. M ás que formar intrincadas tramas geométricas al estilo andaluz, los azulejos brasileños, lo mismo que sus modelos portugueses, armaron grandes escenas piadosas, paisajísticas 0 urbanas que probablemente provienen de grabados europeos.

\section{Lasjóvenes repúblicas iberoamericanas y sus edificaciones}

Todas las naciones iberoamericanas se independizaron durante las primeras dos décadas del siglo xix, con excepción de Cuba (donde el dominio español se prolongó otro siglo) y Brasil. El caso brasileño es singular, porque durante las guerras napoleónicas la corona portuguesa se refugió en Río de Janeiro

48. Graciano Gasparini, op. cit., p. 49.

49. Exceptuando algunas capillas rurales en el Altiplano Central que aún conservan este sistema, en M éxico casi no quedan ejemplos importantes de caballetes de par y nudillo. Por eso mismo sorprende su profusión en el resto de Iberoamérica. 
I2. "M edio punto" en una residencia sobre la Plaza Vieja, La H abana. Vitrales del siglo xix. Foto: Alberto González Pozo.

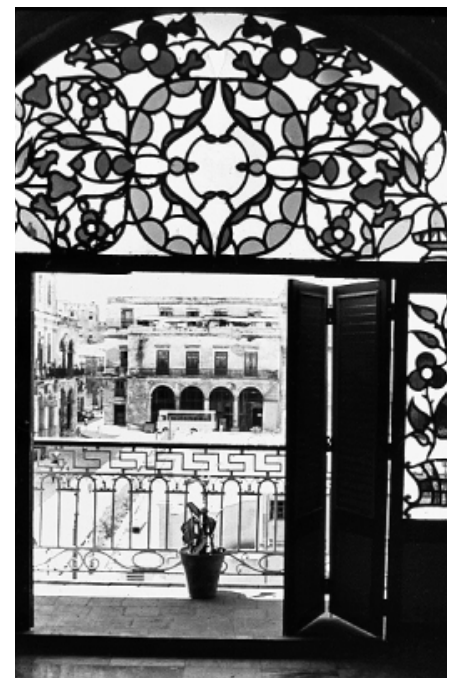

temporalmente, dándoles a sus dominios brasileros un status semejante al de sus provincias peninsulares hasta 1830. Luego dejó una dinastía de la casa de Braganza al frente del Brasil, convirtiéndolo en imperio autónomo que funcionó hasta I88o, año en que finalmente surgió la república en una transición incruenta. Estos hechos aseguraron en Cuba y en Brasil un esfuerzo edificatorio decimonónico más sostenido que el del resto de las jóvenes repúblicas latinoamericanas, más ocupadas en guerras intestinas o de defensa de sus territorios.

En ese contexto, la arquitectura y el urbanismo latinoamericanos durante el siglo xix responden a pocas tipologías europeas - en gran medida a cargo de arquitectos del mismo origen - que se inician con el neoclásico, prosiguen con otros neoestilos (neogótico, neorrománico, neomorisco) y culminan, ya en el tránsito hacia el siglo $\mathrm{xx}$, con el eclecticismo.50 Sin embargo, crece el número de estudios que detectan procesos de adaptación de esas tipologías a las condiciones ambientales, tecnológicas y culturales imperantes en cada región, lo que produjo respuestas - no siempre perceptibles a primera vistaque muestran ingenio y una buena dosis de creatividad.

50. La siguienteetapa, el art nouveau, no surgió en América Latina sino hastalas primeras dé cadas del siglo xx, aunque ya había dado comienzo en la Europa finisecular decimonónica. 
El peso del neoclásico es innegable, como en la fachada de la catedral de Buenos Aires (1822), de Próspero Catelín, con su pórtico dodecástilo de orden corintio soportando entablamento y frontón..$^{5 \mathrm{O}} \mathrm{O}$ tros ejemplos relevantes son El Templete de Antonio de la Torre en La H abana (I827) 0 la Iglesia del Salvador en Arequipa, Chile (I842).52 Ya en la segunda mitad del siglo xIx, un arquitecto emigrado de Italia, Luis Caravati, proyecta entre I859 y I886 otro racimo de ejemplos neoclásicos: la Catedral, la Casa de Gobierno Provincial, el Seminario Conciliar y el H ospital San Juan Bautista, todos en Catamarca, Argentina.53 Por la misma época, los suizos ticineses Agustín y Tomás Cánepa también emplearon ese estilo en la Catedral y el Cabildo de Santiago del Estero, Argentina. 54

Sin duda, hubo otras aplicaciones del neoclásico decimonónico y sus variantes tardías, por ejemplo, en el C apitolio $\mathrm{N}$ acional de Colombia en Bogotá, de Tomás Reed, proyectado en I847 y concluido ochenta años más tarde con algunas modificaciones, como la supresión del frontón sobre el peristilo de orden jónico.55 M uchos otros edificios institucionales adoptaron un ropaje neoclásico, como la Cámara de Comercio (I8I5) en Salvador de Bahía, Brasil, o el Cabildo (I842), diseño de Pascual U rdapilleta en Asunción, Paraguay, ${ }^{56}$ y algunos de ellos comenzaron a competir en volumen 0 en altura con las iglesias, que en la época colonial habían sido las edificaciones dominantes. El ejemplo más sobresaliente de esta secularización de la arquitectura de la segunda mitad del siglo xix es el Palacio del Congreso en Buenos Aires, proyectado por Víctor M eano en i898,57 cuya altura sobrepasó a todos los demás edificios de su época. La misma aspiración se advierte incluso en pequeñas localidades como Sololá, Guatemala, donde el modesto palacio municipal

5I. Mario J. Buschiazzo, La arquitectura en la República Argentina, 1819 1930, Buenos Aires, Mac Gaul, 1971, p. 8.

52. M yriam Waisberg, "Valparaíso", en Centros históricos. América Latina., op. cit.

53. Alberto Nicolini, "C atamarca", en Sociedad Central de Arquitectos e Instituto Argentino de Investigaciones en $\mathrm{H}$ istoria de la Arquitectura y el Urbanismo, El patrimonio histórico de los argentinos, Buenos Aires, Sociedad Central de Arquitectos, 1987, pp. 94-99.

54. Rodolfo O. Legname, y M arta B. Silva, "Santiago del Estero", en Sociedad Central de Arquitectos e Instituto Argentino de Investigaciones en $\mathrm{H}$ istoria de la Arquitectura y el U rbanismo, op. cit., pp. 70-71.

55. Silvia Arango, op. cit., pp. ro6-ıाо.

56. Ramón Gutiérez, op. cit., pp. 365-40I.

57. M ario J. Buschiazzo, op. cit., p. 44. 


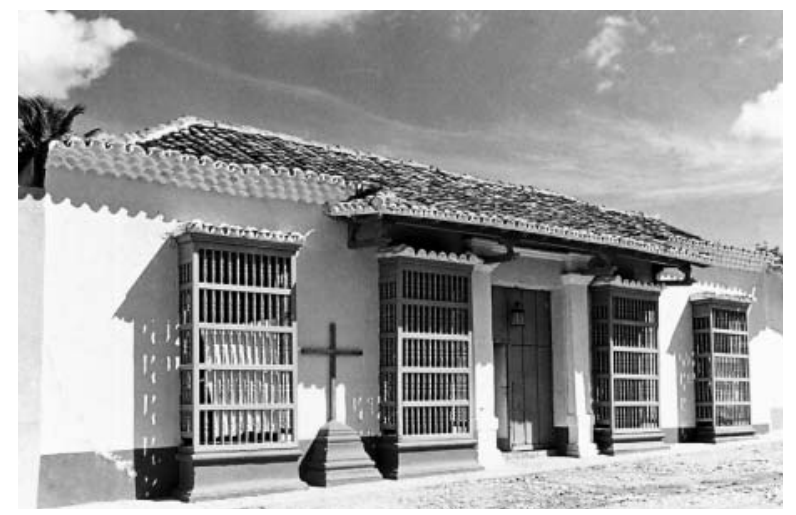

I3. C asa del siglo xviı, Trinidad, Cuba. Foto: Alberto González Pozo.

ostenta orgulloso su torre de reloj con las proporciones de un soberbio campanario eclesial.

EI neoclásico también aparece, más imaginativo, en programas culturales como el notable Teatro Solís de M ontevideo, U ruguay (I84I), de Carlo Zucchi, o el de $\mathrm{Q}$ uetzaltenango, la Atenas guatemalteca. $\mathrm{H}$ ay muchos otros teatros dignos de mención, pero entre ellos sobresalen el Teatro Colón de Buenos Aires, que tuvo dos versiones: la primera, desaparecida, proyectada en I857 por Carlos Enrique Pellegrini, que ya tenía estructura metálica, y la definitiva, proyectada en 1889 por Francisco Tamburini, que es un escenario de artes interpretativas de rango mundial..$^{58}$

N eoclásicas fueron, también, edificaciones domésticas como "El C aserón" del caudillo Juan M anuel de Rosas en Palermo, Buenos Aires (ya desaparecido), o muchas fachadas de viviendas de los barrios que se extendieron en el siglo xix fuera del núcleo urbano original de La H abana, donde el paisaje urbano lo formaban clásicos portales de columnas y dinteles descritos magistralmente por Alejo Carpentier. 59

El neoclásico también se extendió a través de obras públicas muy populares, como las fuentes-lavadero de Guatemala (donde hubo ejemplos sobrios y

59. Alejo Carpentier, La ciudad de las columnas, M éxico, Fondo de Cultura EconómiCa, I970. 
monumentales de la época colonial, como la que existe en el centro de Antigua), pero que en el siglo xix adoptaron formas helenísticas, como en Totonicapan. Ese neoclásico al servicio de tareas cotidianas también está en la Alhóndiga de Salvador de Bahía, Brasil, con su mercado semicircular abierto. También aparece en los ingresos a algunos panteones civiles, como el del Pilar en Salvador de Bahía (I8I5), o en su homólogo en Rosario, Argentina (I876).60 Esta apropiación popular de un prestigioso estilo ya había ocurrido con el barroco, así que no extraña la multitud de aplicaciones que se le encontraron al neoclásico en toda América Latina.

El periodo neomedieval y sus variantes (neorrománico, neogótico), así como la corriente neomorisca son menos frecuentes, pero no por ello carecen de interés. D estacan los ejemplos de la Baślica de Luján, de U Irico Courtois, y la Catedral de La Plata, de Pedro Benoit (ambas iniciadas a fines del siglo XIx, en Argentina), ${ }^{61}$ así como las iglesias de Sandoná, Nariño, de U baté, Cundinamarca y la Ermita de $\mathrm{C}$ ali, todas en Colombia. ${ }^{62}$

0 tra tipología característica del siglo xix (pero que proviene del anterior) es la de las disposiciones panópticas que se adoptaron para reclusorios, hospitales y otros equipamientos donde se buscaba controlar visualmente a grupos determinados. Entre los primeros ejemplos destaca la Cárcel Panóptica (hoy M useo N acional) de Bogotá, de Tomás Reed, que era un proyecto de I846 con alas convergentes, ejecutado 25 años más tarde por Guerra Azuola y O laya. ${ }^{63}$ También responden a esa tipología el Hospital Dos de $M$ ayo en Lima (I868-1875) de M ateo Graziani, ${ }^{64}$ el Penal de Recife y la Penitenciaría Nacional de Buenos Aires (I876) de Ernesto Bunge. ${ }^{65}$

\section{El urbanismo decimonónico}

El ingreso de América Latina al mundo de la globalización comienza a partir de la conquista de su territorio por potencias europeas en el siglo xvi. Y el si-

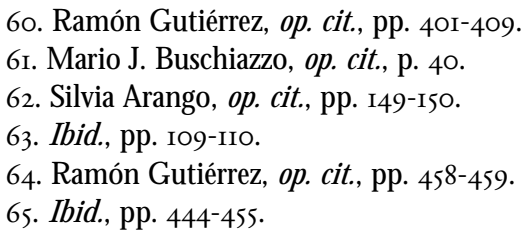


glo xix aceleró más ese proceso. El urbanismo decimonónico, inspirado por nuevos intereses y reglas, donde la renta del suelo y la obtención de plusvalía se obtenían más fácilmente en las áreas de crecimiento urbano, que pronto comenzaron a desbordar los límites del antiguo orden urbano colonial. En ese contexto, el impacto del transporte colectivo fue decisivo. Movidos al principio por tracción animal, luego, durante un breve periodo, por máquinas de vapor y finalmente, ya en el siglo $\mathrm{xx}$, por tranvías eléctricos cada vez más grandes y veloces, esos sistemas de transportación facilitaron la explosión urbana que comenzó a registrarse en toda América Latina, especialmente en las grandes capitales, lo mismo Río de Janeiro ${ }^{66}$ y São Paulo que Buenos Aires o la ciudad de M éxico. ${ }^{67}$ Son historias paralelas que conviene conocer y comparar para reconocer los rasgos comunes de movilidad que fueron estructurando el espacio urbano.

$M$ ás interesantes resultan los primeros intentos en la última década del siglo xix por reunir esas experiencias en proyectos de ciudades nuevas, como La Plata en Argentina y Belo $\mathrm{H}$ orizonte en Brasil. La Plata es fruto de un programa integral muy completo promovido en 1882 por $D$ ardo Rocha y trazado por Pedro Benoit ${ }^{68}$ para una ciudad con una corona de establecimientos rurales y hortícolas, donde la zona urbana es circundada y penetrada por vías férreas que llegan a dos terminales cerca del centro. Su traza combina un orden rigurosamente ortogonal con generosas diagonales, entonces muy de moda tanto en Europa como en Estados U nidos, lo mismo que en otras ciudades como Buenos Aires y Córdoba, que introdujeron esos trazos poco antes. Su condición de capital de la provincia de Buenos Aires proveyó a La Plata de equipamientos administrativos provinciales y municipales que la hacían una ciudad burocrática. Su diseño urbano dispuso tantos parques como edificios públicos necesitasen de ese tipo de entorno para lucir mejor su

66. El caso de la expansión urbana de Río de Janeiro durante los siglos xix y xx y su relación con los sistemas de transporte público está descrito magistralmente en $M$ auricio de Almeida Abreu, Evoluçao U rbana do Rio de Janeiro, za ed., Río de Janeiro, iplanrio-Jorge Zahar, 1988.

67. M aría D olores M orales, "La expansión de la ciudad de M éxico en el siglo xix: el caso de los fraccionamientos", en Alejandra M oreno Toscano (coord.), Ciudad de M éxico. Ensayo de construcción de una historia, M éxico, Instituto Nacional de Antropología e Historia, 1978, pp. 189-216.

68. M ario J. Buschiazzo, op. cit. 
DOI: http://dx.doi.org/10.22201/iie.18703062e.2004.85.2412

II6

imagen de servicio. En consecuencia, La Plata es hoy una de las ciudades decimonónicas latinoamericanas más generosamente dotadas de espacios verdes.

Belo H orizonte (1895) es el ejemplo brasileño contemporáneo a La Plata donde también se aprecia una retícula ortogonal precisa, cruzada por algunas diagonales y circundada por vías férreas. También hay abundancia de áreas verdes, aunque más concentradas en pocas zonas. ${ }^{69}$ Conociendo ambos ejemplos, se advierte la influencia común del proyecto urbano de L'Enfant para Washington, pero también cabría indagar respecto a posibles influencias del proyecto del Ensanche para Barcelona de Ildefonso Cerdá sobre estos magníficos diseños urbanos. ${ }^{\circ}$

\section{La arquitectura de la Revolución Industrial}

El impacto de la Revolución Industrial llegó tarde a Latinoamérica, pero pronto hizo sentir sus efectos. Se desarrollaron nuevos géneros y maneras de construir que siguieron evolucionando hasta el siglo xx. También surgieron nuevas formas de energía capaces de acelerar los procesos de producción. Todo transformó la eficiencia, el tamaño y la variedad de fábricas, siderúrgicas, refinerías, astilleros. $\mathrm{H}$ asta mediados del siglo xix, las edificaciones necesarias para la industria podían ser de maderamen. El hierro, la lámina de zinc y el vidrio industrializados no aparecieron sino más tarde, pero pronto se convirtieron en el material constructivo básico de esas edificaciones, conviviendo con sistemas tradicionales de mamposterías que se conservaron para muros divisorios, fachadas y algunos ornamentos. Con mamposterías externas se llegó incluso a dar fisonomía medieval a algunas fábricas como una en Bahía Blanca, Argentina, en las postrimerías del siglo xix. ${ }^{71} \mathrm{M}$ uchas de esas prime-

69. M arco Aurelio A. deFilgueiras G omes y Fabio J osé M artins de Lima, "Pensamento eprática urbanística em Belo H orizonte, I895-196I", en M aria Cristina da Silva Leme (coord.), U rbanismo no Brasil, 18951965, São Paulo, Studio N obel-fauUsP-FupAM, I999, pp. I20-I40.

70. Habría que recordar que Cerdá había estudiado acuciosamente el desarrollo urbano de las principales ciudades iberoamericanas y que sus avanzadas tesis trataban de recobrar, actualizándolas, las experiencias del urbanismo español en ultramar, particularmente en los casos de Buenos Aires (Argentina) y Cienfuegos (C uba). Cfr. Arturo Soria y Puig (comp.), Cerdá. Las cinco bases de la teoría general de la urbanización, Barcelona y M adrid, Fundació Catalana per la Recerca-Electa España, 1996.

7I. Ramón Gutiérrez, op. cit., p. 53I. 
ras edificaciones industriales han desaparecido, pero quedan varias de las que se construyeron para los sistemas de transportación regional, terminales ferrocarrileras que se levantaron en la segunda mitad del siglo xix, como la Estación Central de Asunción, Paraguay (I864), la segunda Estación del Fe rrocarril Central de M ontevideo, U ruguay (I897), la tercera Estación Central de Santiago de Chile, del mismo año, ${ }^{72}$ y la magnífica Estación La Luz de São Paulo, Brasil (I900), actualmente reutilizada como centro cultural. 0 tras estaciones todavía más grandes y espectaculares se construyeron en Río, São Paulo, Buenos Aires y Bogotá ya en el siglo xx.

La industrialización también propició un mejoramiento palpable en las infraestructuras urbanas, que pudieron expandirse vigorosamente gracias a la disponibilidad de partes prefabricadas para sus centrales, sus equipos y sus redes. Así, comenzaron a construirse grandes depósitos el evados de agua, a base de placas de hierro, como el dePelotas, Brasil (I875). Eran útiles, sin duda, pero muy feos, por mucho que se adornaran con elementos decorativos de hierro forjado. Q uizá por eso algunos se ocultaron detrás de fachadas de edificios convencionales, como la cisterna de $\mathrm{M}$ anaos (1899). ${ }^{73} \mathrm{El}$ inmueblemás significativo de este tipo es el Palacio de Las Aguas Corrientes: una gigantesca cisterna dividida en compartimentos de placas de hierro en pleno centro de Buenos Aires, que por fuera se percibe como elegante edificio público de varios niveles, con su fachada neorrenacentista donde muchos de sus vanos están cegados o sólo iluminan una circulación en torno a ese depósito hidráulico. ${ }^{74}$

Los sistemas de construcción que surgieron con la Revolución Industrial propiciaron nuevos programas de equipamientos, por ejemplo para el comercio popular: sólo en Buenos Aires, entre 1823 y 1900 se construyeron 36 mercados públicos (la mayoría después de 1850), entre ellos el gran M ercado de Abasto. En ellos se emplearon estructuras de hierro que posibilitaron grandes claros y diversas formas de iluminación cenital. 75 O tro tanto ocurrió en Bra-

72. Jorge D. Tartarini, Arquitectura ferroviaria, Buenos Aires, Colihue, 200I, pp. 37-59.

73. G eraldo G omes da Silva, Arquitetura do ferro no Brasil, São Paulo, N obel, 1987, pp. 94-97.

74. Ernesto Maeder (dir.) y Ramón Gutiérrez (dir. de inv.), El Palacio de las Aguas Corrientes: monumento histórico nacional, Buenos Aires, Patrimonio H istórico-Aguas Argentinas, 1996.

75 Raúl E. Piccioni, "Las tipologías de los mercados", en DANA (D ocumentos de Arquitectura Nacional y Americana), Buenos Aires, Instituto Argentino de Investigaciones de $\mathrm{H}$ istoria de la Arquitectura y del U rbanismo, núm. 25, 1988, pp. 32-4I. 
sil, donde aún subsisten mercados armados con elementos de hierro prefabricados en Francia, como el M ercado San José en Recife (I875)..$^{76}$

Era sólo el comienzo de los sistemas constructivos que caracterizarían a mucha de la arquitectura del siglo xx. Porque si bien los prefabricados de hierro colado siguieron empleán dose hasta la Primera Guerra M undial, al final serían sustituidos por otros materiales: acero, aluminio, concreto, plásticos. Y lo mismo ocurriría con el eclecticismo que imperó en los edificios más prestigiosos del ámbito latinoamericano: terminaría por dar paso a los intentos del art nouveau, del nacionalismo, del art déco y del movimiento moderno. Pero también en esa transición hubo particularidades regionales que merecen consignarse en otro artículo que se enlazará cronológicamente con éste que ahora termina. \& 